\title{
BMJ Open Effectiveness of case management interventions for frequent users of healthcare services: a scoping review
}

\author{
Catherine Hudon, ${ }^{1,2}$ Maud-Christine Chouinard, ${ }^{3,4}$ Mireille Lambert, ${ }^{4}$ \\ Isabelle Dufour, ${ }^{3}$ Cynthia Krieg ${ }^{5}$
}

To cite: Hudon C, Chouinard M-C, Lambert M, et al. Effectiveness of case management interventions for frequent users of healthcare services: a scoping review. BMJ Open 2016;6:e012353.

doi:10.1136/bmjopen-2016012353

- Prepublication history and additional material is available. To view please visit the journal (http://dx.doi.org/ 10.1136/bmjopen-2016012353).

Received 19 April 2016 Revised 30 June 2016 Accepted 7 September 2016

\section{CrossMark}

For numbered affiliations see end of article.

\section{Correspondence to}

Professor Catherine Hudon; Catherine.Hudon@

Usherbrooke.ca

\section{ABSTRACT}

Objective: Frequent users of healthcare services are a vulnerable population, often socioeconomically disadvantaged, who can present multiple chronic conditions as well as mental health problems. Case management $(\mathrm{CM})$ is the most frequently performed intervention to reduce healthcare use and cost. This study aimed to examine the evidence of the effectiveness of CM interventions for frequent users of healthcare services.

Design: Scoping review.

Data sources: An electronic literature search was conducted using the MEDLINE, Scopus and CINAHL databases covering January 2004 to December 2015. A specific search strategy was developed for each database using keywords 'case management' and 'frequent use'.

Eligibility criteria for selecting studies: To be included in the review, studies had to report effects of a CM intervention on healthcare use and cost or patient outcomes. Eligible designs included randomised and non-randomised controlled trials and controlled and non-controlled before-after studies. Studies limited to specific groups of patients or targeting a single disease were excluded. Three reviewers screened abstracts, screened each full-text article and extracted data, and discrepancies were resolved by consensus.

Results: The final review included 11 articles evaluating the effectiveness of CM interventions among frequent users of healthcare services. Two non-randomised controlled studies and 4 beforeafter studies reported positives outcomes on healthcare use or cost. Two randomised controlled trials, 2 before-after studies and 1 non-randomised controlled study presented mitigated results. Patient outcomes such as drug and alcohol use, health locus of control, patient satisfaction and psychological functioning were evaluated in 3 studies, but no change was reported.

Conclusions: Many studies suggest that CM could reduce emergency department visits and hospitalisations as well as cost. However, pragmatic randomised controlled trials of adequate power that recruit the most frequent users of healthcare services are still needed to clearly confirm its effectiveness.

\section{Strengths and limitations of this study}

- This article is the first to review the evidence of case management (CM) for a general population of frequent users of healthcare services.

- Although CM activities were well described in the studies, key elements associated with successful $\mathrm{CM}$ interventions were scarcely discussed and will deserve more attention in further studies.

- Emergency department visits of frequent users show a natural decrease over time and regression to the mean may bias outcomes measured in before-after studies.

- Pragmatic randomised controlled trials of adequate power and using good case finding strategies are still needed.

\section{INTRODUCTION}

Industrialised countries have recognised that a small number of patients account for a large proportion of healthcare costs. ${ }^{1-3}$ These patients use emergency department (ED) repeatedly, but their definition varies across studies. ${ }^{4}{ }^{5}$ They also frequently use hospital services for increasingly complex health needs ${ }^{6-8}$ arising from factors such as multimorbidity, psychiatric comorbidities and psychosocial issues, or a combination of these factors. $^{79}{ }^{10}$ Requiring care and services from many partners in the health and social services care system as well as the community care network, frequent users are more likely to encounter difficulties in the integration of care ${ }^{11}$ and more at risk for incapacity and mortality. ${ }^{12}$ Healthcare providers often feel limited in their interventions with this clientele because of patients' complex needs, fragmentation of care and the episodic nature of their visits to ED. ${ }^{13} \mathrm{In}$ this context, patients receive suboptimal care and healthcare systems are overwhelmed by the rising costs. ${ }^{14}$

To address this issue, case management $(\mathrm{CM})$ is the most frequently performed intervention to reduce healthcare use and cost, 
and to provide better care. ${ }^{45}{ }^{15} \mathrm{CM}$ is a collaborative approach used to assess, plan, facilitate and coordinate care to meet patient and family health needs through communication and available resources with the intent to improve individual and health system outcomes. ${ }^{16} \mathrm{CM}$ has been shown to improve satisfaction and quality of life $^{17}$ and to reduce costs associated with frequent users of services. ${ }^{1}{ }^{4-6}{ }^{17-20}$ The National Case Management Network of Canada ${ }^{16}$ defined six standards of practice in CM: (1) determining and verifying patient eligibility for CM; (2) assessing patient needs; (3) documenting patient goals and priorities in a concerted strategy of intervention; (4) planning and adjusting services included in individualised service plans, including patient education and self-management support; (5) periodically reassessing patient needs and progresses; and (6) supporting transition process.

Three systematic reviews ${ }^{4}{ }^{5} 15$ reported the effectiveness of CM interventions among frequent ED users and concluded they had variable benefits on clinical, social and organisational outcomes such as ED use and cost. Two reviews reported different kinds of interventions, including CM. Althaus $e t a l^{4}$ included studies conducted before 2010, while the review by Soril et $a l^{15}$ did not report patient outcomes. Finally, the third review by Kumar and Klein ${ }^{5}$ looked at effectiveness of CM interventions but included articles concerning specific subgroups of patients such as psychiatric populations or patients with psychosocial problems.

Considering that many relevant studies ${ }^{13}{ }^{21-24}$ were not included in these reviews, we aimed, in our review, to examine evidence regarding the effectiveness of $\mathrm{CM}$ interventions among a more encompassing population of frequent users of healthcare services.

\section{METHODS}

Scoping review methodology is recognised as a process of mapping the main concepts of a research area to their source and evidence available in the literature. ${ }^{25} 26$ It also serves to identify gaps in the field and provide recommendations for implementation. ${ }^{25}$ This scoping review followed the five key phases of Arksey and O'Malley: ${ }^{25}$ (1) identifying the research question; (2) identifying relevant studies; (3) selecting studies; (4) charting the data; and (5) collating, summarising and reporting the results.

\section{Research question}

Based on the expertise of our research team and an initial review of the literature, we defined the following research question:

What is the evidence for the effectiveness of CM interventions among frequent users of healthcare services?

\section{Search strategy}

We conducted an electronic literature search of the MEDLINE, Scopus and CINAHL databases for English and French articles published between January 2004 and December 2015. The following MeSH terms and key words were used: case management, disease management, patient care management, patient care planning, health care services misuse, utilization review, frequent attend $\$$, frequent consult $\$$, frequent use $\$$, high utilize $\$$, high consult $\$$, high attend $\$$, high use, repeat use, frequent flyer, heavy use $\$$, repeat $\$$, recidivist, revolving door, misuse and hyperuse. We also examined reference lists of reviewed articles for additional relevant articles (hand searching). The search identified 2717 potentially relevant articles.

\section{Study selection}

To be included in the review, studies had to (1) report effectiveness of an intervention of CM for adult frequent users of healthcare services and (2) describe some form of comparison between patients who receive $\mathrm{CM}$ to those who do not receive the intervention (ie, randomised and non-randomised controlled trials, beforeafter studies) or between patients in preintervention and postintervention (same patients). The outcomes of interest were healthcare use and cost as well as patientreported measures, such as quality of life and patient experience of care. To increase homogeneity and comparability among studies, we excluded studies limited to psychiatric, geriatric, paediatric, homeless, addicted patients or focusing on a single disease.

First, titles and abstracts were reviewed by one team member (ML) to exclude articles that were not eligible. At this stage, we excluded references clearly not meeting our inclusion criteria and retained all other references for analysis. In case of doubt, the full article was submitted to other team members (CH and M-CC) for a more detailed evaluation. Disagreement among team members (ML, CH and M-CC) was resolved by consensus. Forty-two articles were retained for detailed evaluation by team members (ML, CH and M-CC) and one additional reference was identified by hand searching. Of these 43 articles, 32 were excluded: 13 evaluated $\mathrm{CM}$ intervention designed for a specific population of frequent users (psychiatric, geriatric, paediatric, homeless or addicted patients), nine were disease-oriented interventions (mainly on diabetes, chronic obstructive pulmonary disease, rheumatoid arthritis, stroke and heart failure), eight evaluated interventions other than $\mathrm{CM}$, one did not target frequent users and one was a commentary paper. A final sample of 11 articles was retained for data extraction (figure 1).

\section{Data extraction}

For each paper included, we collected descriptive characteristics such as first author and year of publication, study location and population, setting, aim and design of the study, characteristics of the intervention (including type of activities and case manager profession), length of follow-up and data about effectiveness of the intervention. 


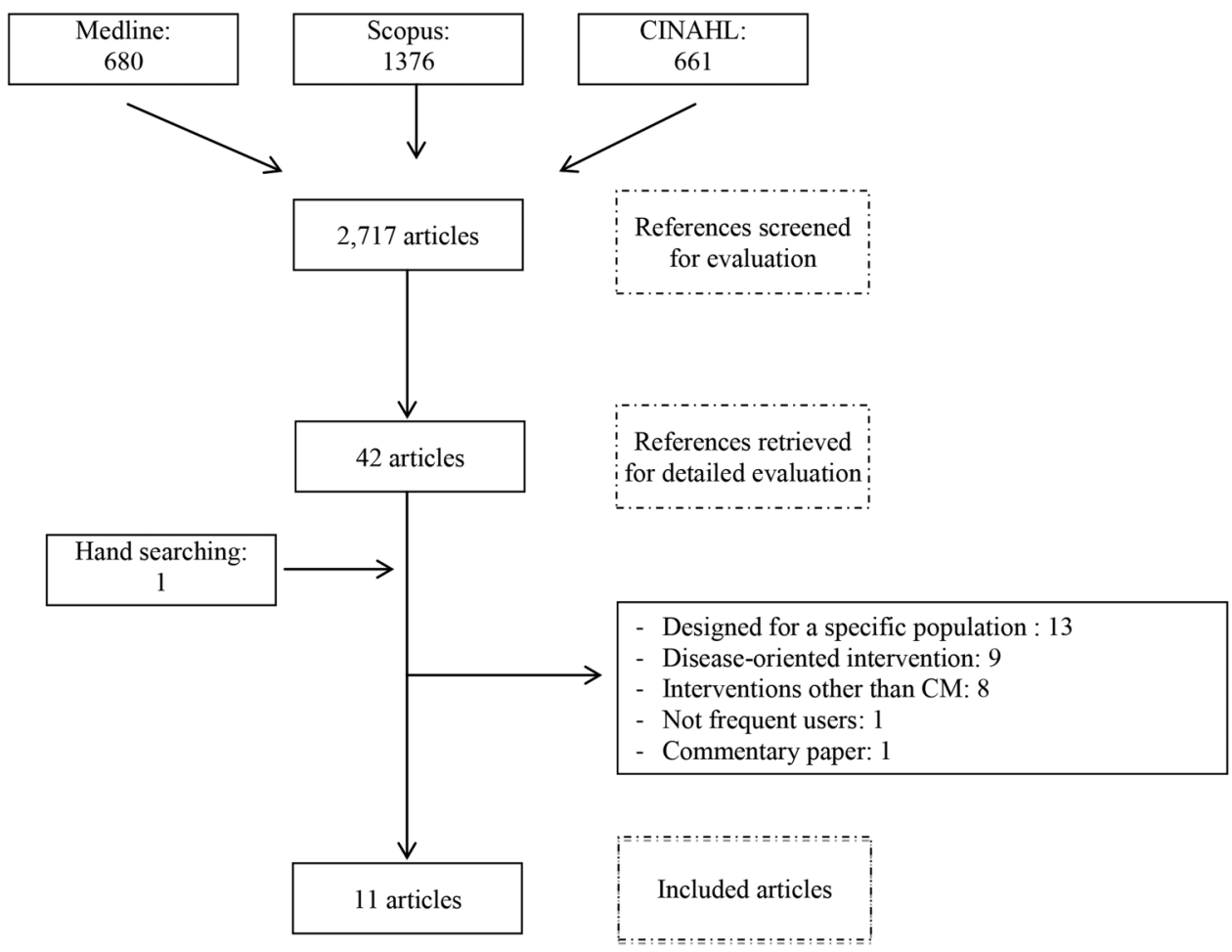

Figure 1 Scoping review flow chart of search results.

\section{RESULTS}

\section{Description of the included studies}

The characteristics of the 11 included papers are shown in table $1 .^{10} 13$ 21-24 27-31 Two papers were randomised controlled trials, three were non-randomised controlled studies and six were before-after studies. The number of participants varied from 10 to 2742, their mean age ranged from 35 to 65 years and the proportion of female varied from $36 \%$ to $74 \%$. Most studies were carried out in the USA $(n=8)$. CM intervention was conducted in $\mathrm{ED}(\mathrm{n}=6)$, primary care (2), in-patient (1) and emergency medical services (EMS) (2).

Definitions of frequent users varied across the 11 studies and were based on number of patient ED visits (ranging from 3 visits in a month to 10 visits in a year), ${ }^{10} 13$ 27-31 number of patient admissions (ranging from two to more than four admissions in a year), ${ }^{23} 30$ number of EMS uses (10 transports or more in 1 year or the top 25 frequent users), ${ }^{21}{ }^{24}$ annual hospital cost (\$4000 and more in a year) ${ }^{22}$ and opinion of the healthcare staff. ${ }^{10}{ }^{24}$ Three studies recruited low-income, uninsured frequent users. ${ }^{27} 30 \quad 31$ Nurses were the case manager in four studies, ${ }^{23} 272831$ social workers in two studies $^{30}$ and paramedic staff in one study, ${ }^{24}$ but majority of the studies $(n=5)$ did not specify who the case manager was.

The CM intervention also varied across studies (table 2). All interventions assessed patient needs as well as planned and adjusted services included in individualised service plans. The majority determined and verified patient eligibility $(n=10)$, supported transition process $(n=8)$, reassessed patient needs and progress $(\mathrm{n}=7)$, and provided patient education and self-management support $(\mathrm{n}=6)$. Few studies documented patient goals and priorities $(n=3)$ (see online supplementary appendix 1 ).

As indicated in table 3, all studies reported the use of care as an outcome, six studies evaluated healthcare $\operatorname{cost}^{21-242730}$ and three studies investigated the impact of a CM intervention on patient quality of life. ${ }^{22} 23 \quad 31$ Only one study evaluated healthcare use and cost as well as patient quality of life..$^{23}$

\section{Healthcare use and cost}

Among all the studies included, two described results of a randomised control trial. ${ }^{22} 23$ In a study of 2742 patients with high levels of in-patient healthcare expenditures, Segal et $a l^{22}$ showed an increase in healthcare cost mainly due to the extra costs for care planning and CM. However, the experimental group included only 5\% of patients at risk of future hospital admission. This could indicate a problem in the selection of their patients who should represent frequent users. In a randomised controlled trial of 96 patients, Sledge et $a t^{23}$ observed a trend towards reduced admission, ED use and total healthcare cost in the experimental group, but they found that the difference was not significant, probably due to a lack of power.

Three articles presented non-randomised controlled studies. ${ }^{27} 28{ }^{30}$ Shah $e t a l^{30}$ conducted a study with 258 low-income, uninsured patients and demonstrated that ED use as well as cost had significantly decreased, but no difference was reported for in-patient admissions. The authors attributed positive results to patient engagement, frequent in-person contacts, liaison with social 
Table 1 Characteristics of the studies included

\begin{tabular}{|c|c|c|c|c|c|}
\hline Source (location) & Design & Setting & Population & $\mathbf{N}$ & Outcomes \\
\hline $\begin{array}{l}\text { Crane et } a R^{7} \\
\text { (USA) }\end{array}$ & $\begin{array}{l}\text { Non-randomised } \\
\text { controlled study }\end{array}$ & ED & Low-income, uninsured frequent ED users (6 ED visits/year) & $\begin{array}{l}\mathrm{I}=36 \\
\mathrm{C}=36\end{array}$ & $\begin{array}{l}\downarrow \\
\downarrow \text { ED use } \\
\downarrow \text { Total healthcare cost-ED and admission } \\
\text { charges }\end{array}$ \\
\hline $\begin{array}{l}\text { Lee and } \\
\text { Davenport }{ }^{10} \text { (USA) }\end{array}$ & $\begin{array}{l}\text { Before-after study } \\
\text { (pilot study) }\end{array}$ & ED & $\begin{array}{l}\text { Frequent ED users ( } \geq 3 \mathrm{ED} \text { visits/month) associated with } \\
\text { symptoms of unresolved pain, drug seeking or lack of primary } \\
\text { care physician }\end{array}$ & 50 & No change on ED use \\
\hline $\begin{array}{l}\text { Peddie et } a^{28} \\
\text { (New Zealand) }\end{array}$ & $\begin{array}{l}\text { Non-randomised } \\
\text { controlled study }\end{array}$ & ED & Frequent ED users ( $\geq 10$ ED visits/year) & $\begin{array}{l}\mathrm{I}=87 \\
\mathrm{C}=77\end{array}$ & No change on ED use \\
\hline $\begin{array}{l}\text { Phillips et } a^{R^{\prime}} \\
\text { (Australia) }\end{array}$ & Before-after study & ED & Frequent ED users ( $\geq 6$ ED visits/year) & 60 & $\begin{array}{l}\text { TED use } \\
\uparrow \text { Primary care engagement } \\
\uparrow \text { Community care engagement } \\
\text { No change on admission ED disposition, ED } \\
\text { length of stay, ED triage category, drug and } \\
\text { alcohol use and EMS use }\end{array}$ \\
\hline $\begin{array}{l}\text { Pillow et } a l^{13} \\
\text { (USA) }\end{array}$ & Before-after study & ED & $\begin{array}{l}\text { Top } 50 \text { chronic ED frequent users (a total of } 94 \text { ED visits/ } \\
\text { month and } 31 \text { admissions/month) }\end{array}$ & 50 & $\begin{array}{l}\downarrow \downarrow E D \text { use } \\
\text { No change on admission }\end{array}$ \\
\hline $\begin{array}{l}\text { Rinke et } a R^{11} \\
\text { (USA) }\end{array}$ & $\begin{array}{l}\text { Before-after study } \\
\text { (pilot study) }\end{array}$ & EMS & Top 25 frequent EMS users & 10 & $\begin{array}{l}\downarrow \downarrow \mathrm{EMS} \mathrm{cost}{ }^{\star} \\
\triangleright \downarrow \mathrm{EMS} \mathrm{use}^{*}\end{array}$ \\
\hline $\begin{array}{l}\text { Segal et } a^{R^{2}} \\
\text { (Australia) }\end{array}$ & $\begin{array}{l}\text { Randomised controlled } \\
\text { trial }\end{array}$ & $\begin{array}{l}\text { In-patient } \\
\text { services }\end{array}$ & $\begin{array}{l}\text { Frequent users of in-patient services ( } \$ \geq 4000 \text { during a 2-year } \\
\text { period) }\end{array}$ & $\begin{array}{l}\mathrm{I}=2074 \\
\mathrm{C}=668\end{array}$ & $\begin{array}{l}\uparrow \text { Total healthcare cost }{ }^{\star} \\
\text { N Hospital-based outpatient cost } \\
\text { quality of life and mortality }\end{array}$ \\
\hline Shah et $a l^{30}$ (USA) & $\begin{array}{l}\text { Non-randomised } \\
\text { controlled study }\end{array}$ & $\begin{array}{l}\text { Primary care } \\
\text { services }\end{array}$ & $\begin{array}{l}\text { Low-income, uninsured frequent ED and inpatient users ( } \geq 4 \\
\text { ED visits or admissions, or } \geq 3 \text { admissions, or } \geq 2 \text { admissions } \\
\text { and } 1 \text { ED visit/year) }\end{array}$ & $\begin{array}{l}\mathrm{I}=98 \\
\mathrm{C}=160\end{array}$ & $\begin{array}{l}\text { } \\
\text { } \downarrow \text { ED use } \\
\text { - } \downarrow \text { Edmission cost } \\
\text { No change on admission and } \\
\text { - Admission length of stay }\end{array}$ \\
\hline $\begin{array}{l}\text { Sledge et } a P^{3} \\
\text { (USA) }\end{array}$ & $\begin{array}{l}\text { Randomised controlled } \\
\text { trial }\end{array}$ & $\begin{array}{l}\text { Primary care } \\
\text { services }\end{array}$ & Frequent users of in-patient services ( $\geq 2$ admissions/year) & $\begin{array}{l}\mathrm{I}=47 \\
\mathrm{C}=49\end{array}$ & $\begin{array}{l}\text { No change on admission, ED use, total healthcare } \\
\text { cost, quality of life and patient satisfaction }\end{array}$ \\
\hline $\begin{array}{l}\text { Tadros et a } \text { P }^{4} \\
\text { (USA) }\end{array}$ & $\begin{array}{l}\text { Before-after study } \\
\text { (pilot study) }\end{array}$ & EMS & $\begin{array}{l}\text { Frequent EMS users ( } \geq 10 \text { EMS transports/year, or referred } \\
\text { by fire and EMS personnel) }\end{array}$ & 51 & 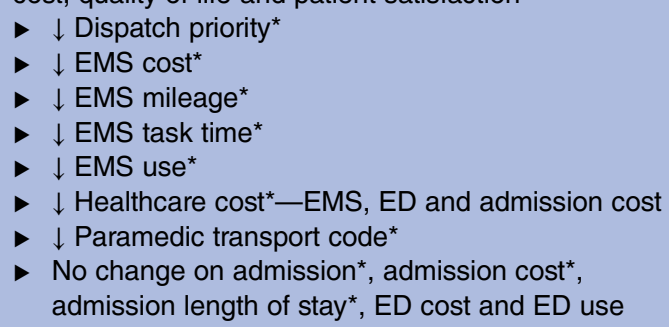 \\
\hline Wetta-Hall ${ }^{31}$ (USA) & Before-after study & ED & $\begin{array}{l}\text { Low-income, uninsured frequent ED users ( } \geq 3 \text { ED visits/ } \\
6 \text { months) }\end{array}$ & 492 & $\begin{array}{l}\downarrow \text { ED use } \\
\uparrow \text { Quality of life } \\
\text { No change on health locus of control }\end{array}$ \\
\hline
\end{tabular}

*Not stated if the outcome was significant or not.

C, Control group; ED emergency department; EMS, Emergency Medical System; I, intervention group. 


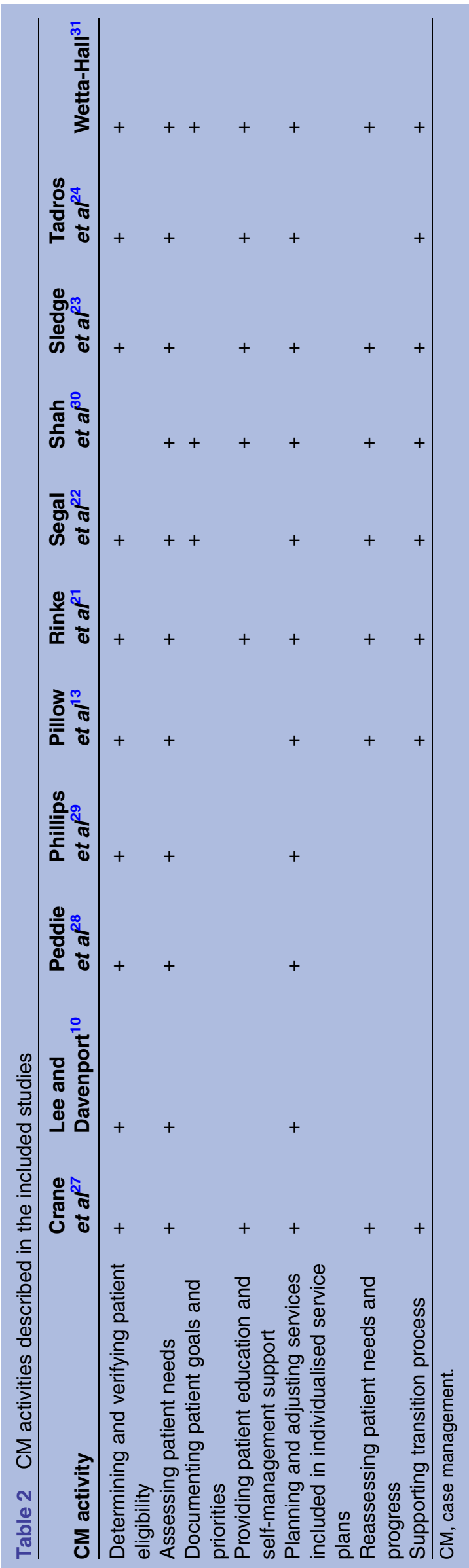

Table 3 Outcomes measured in the included studies

\begin{tabular}{ll}
\hline Outcome & $\begin{array}{l}\text { Number of } \\
\text { studies }\end{array}$ \\
\hline Use of care & 11 \\
ED & 9 \\
ED length of stay & 1 \\
Admission & 4 \\
Admission length of stay & 2 \\
EMS & 3 \\
Primary care services & 1 \\
Care cost & 6 \\
ED & 2 \\
Admission & 3 \\
EMS & 2 \\
Healthcare services (primary, & 4 \\
secondary and supportive care) & \\
Hospital-based outpatient services & 1 \\
Medication & 1 \\
Other & 6 \\
Quality of life & 3 \\
Community care engagement & 1 \\
Drug and alcohol use & 1 \\
ED disposition & 1 \\
EMS dispatch priority & 1 \\
EMS task time & 1 \\
EMS mileage & 1 \\
Health locus of control & 1 \\
Housing status & 1 \\
Mortality & 1 \\
Paramedic transport code & 1 \\
Patient satisfaction & 1 \\
Primary care engagement & 1 \\
Triage category (ED) & 1 \\
\hline ED, emergency department; EMS, Emergency Medical System.
\end{tabular}

resources, and close relationships between case managers, local hospitals and providers at local clinics. However, a possible bias in favour of patients more willing to engage in the management of their health was noted. A study with 36 patients in the experimental group by Crane et $a l^{27}$ also demonstrated a reduction in ED use and healthcare cost ranging from US\$ 1167 per patient per month to US $\$ 230(\mathrm{p}<0.001)$ in combined ED and inpatient hospital charges. The authors identified many factors contributing to the effectiveness of their CM intervention: long and frequent medical visits without limitation on the number, identification and resolution by the care team of barriers and frustrations in accessing medical care, emotional support provided to the patient by the group meetings, and personal qualities and competence of the care manager who gaining patient trust. However, of the 147 frequent users contacted, only 36 accepted to participate, probably the more motivated patients, something that could be seen as a possible bias. Another limitation could be attributed to the analysis of the data that came from only one hospital, although frequent users are known to seek care at multiple EDs. On the other hand, Peddie et $a l^{28}$ 
conducted a non-randomised controlled study with 164 frequent ED users and found no reduction in ED visits. After 4 years of follow-up, the percentage of patients in the experimental group still attending ED at least once a year in the fourth year was similar to the control group (respectively $64 \%$ vs 65\%). The fact that the control group was an historical one, that is, individuals acted as their own controls, and possible lack of power could explain this result.

Six articles described results of before-after studies. ${ }^{10} 13 \quad 21 \quad 24 \quad 29 \quad 31$ Four articles demonstrated a reduction of healthcare use and cost, ${ }^{13} 212431$ and two of them reported no change in ED use or admission. ${ }^{13} 24$ Pillow $e a^{13}$ conducted a study with the top 50 chronic ED frequent users. By using data from one hospital, they reported a trend towards a reduction in ED use, but no significant change on admission. The main factors contributing to their repeat visits according to the CM team were psychiatric disease, substance abuse, malingering, medication non-compliance and unstable housing. In the same way, a before-after study of 60 patients by Phillips $e t a l^{29}$ reported an increase in ED use. Seventy-three per cent of the patients presented either substance misuse or psychosocial issues as their primary problem, and only $27 \%$ had chronic medical problems. In a study of 492 low-income, uninsured frequent ED users, Wetta-Hall ${ }^{31}$ demonstrated a reduction in ED use. The author associated this result to the advocacy role of the CM team who facilitated participant access to medical care, prescription medications and social services. Rinke et $a l^{21} \quad(\mathrm{n}=10)$ and Tadros et $a l^{24} \quad(\mathrm{n}=51)$ observed a reduction in EMS cost and use among frequent EMS users. However, Tadros $e t a l^{4}$ reported no change on admission as well as ED use and cost. Finally, in a pilot study with 50 patients, Lee and Davenport ${ }^{10}$ found no change in ED use.

\section{Patient-reported outcomes}

Among the three studies reporting quality-of-life outcomes, ${ }^{22} 2331$ two randomised controlled trials reported no change, ${ }^{22} 23$ one of them included only $5 \%$ of patients at risk of future hospital admission ${ }^{22}$ and the other possibly lacked power with a sample of 96 patients. ${ }^{23}$ One before-after study found an improvement in patient quality of life. ${ }^{31}$ Wetta-Hall $^{31}$ demonstrated that the physical dimension of quality of life improved significantly after the $\mathrm{CM}$ intervention $(p<0.001)$. However, the mental dimension of the quality-of-life score showed minimal change. Physical dimension of quality of life probably improved due to the fact that the participants had access to medical care, prescription medications and social services. According to the author, mental dimension of quality of life did not change because it was not the focus of the CM intervention. Moreover, life circumstances of a low-income, less educated and uninsured population did not change between preintervention and postintervention.
Patient outcomes such as drug and alcohol use, health locus of control and patient satisfaction were evaluated in three studies, ${ }^{23} 2931$ but no change was reported.

\section{DISCUSSION}

This scoping review identified 11 studies evaluating the effectiveness of CM interventions among frequent users of healthcare services. Two non-randomised controlled

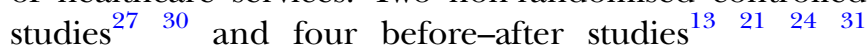
reported positive outcomes on healthcare use or cost. However, a selection bias may have been present in four studies because their participants were probably more motivated to change behaviour given their willingness to participate in the intervention. ${ }^{21} 273031$ In addition, four studies included a small sample of patients $(\leq 51),{ }^{13} \quad 2124 \quad 27$ and three studies conducted their analyses on data from only one hospital. ${ }^{13} 2427$ On the other hand, five studies presented mitigated results. ${ }^{10} 22232829$ One of the randomised controlled trials $^{23}$ was unable to detect a difference in healthcare cost and use, while the other demonstrated an increase in healthcare $\operatorname{cost}^{22}$ but raised issues concerning case finding. One before-after study ${ }^{29}$ found an increase in ED use, but this was probably due to high levels of participants with substance abuse or psychosocial problems. A non-randomised controlled study ${ }^{28}$ and a before-after study $^{10}$ reported no change in ED use, but possibly lacked power. Patient outcomes such as drug and alcohol use, health locus of control, patient satisfaction and psychological functioning were evaluated three studies, but no change was reported. ${ }^{23} 2931$

A majority of the studies included a detailed description of their intervention and CM activities were clearly identified. 'Documenting patient goals and priorities' was the activity less frequently reported. Many interventions did not consider patient health objectives in individualised services plan ${ }^{132123242728}$ even if goal setting is recognised as an important component of $\mathrm{CM}^{16}$ Although CM activities were well described in the studies included, key elements associated with successful CM interventions were scarcely discussed. Considering their complexity, it is essential to understand the main mechanisms underlying $\mathrm{CM}$ activities and go beyond the cause-effect relationship by including a process evaluation considering the influence of contexts on outcomes. ${ }^{32}$ An explanatory analysis on how CM intervention works, in what populations/subpopulations, and in what circumstances and contexts is necessary to identify modifiable factors influencing intervention effects. ${ }^{33}$ These results would be very relevant for researchers and decision-makers who plan to implement $\mathrm{CM}$ interventions.

The studies included pointed out several problems in assessing the efficacy of $\mathrm{CM}$ interventions designed to manage frequent users. First, ED visits of frequent users show a natural decrease over time 23283435 and regression to the mean may bias outcomes ${ }^{36}$ measured in 
before-after studies that demonstrated a reduction in ED use. ${ }^{13} 273031$ Pragmatic randomised trials may help to attribute a reduction in use of care for frequent users of $\mathrm{CM}$ interventions and produce results that can be generalised to clinical practice settings, more than in a traditional controlled randomised trial. ${ }^{37}$ Second, case finding, that is, the identification of participants who will benefit the most from the intervention, could also affect results as shown in the study by Segal $e t a l^{22}$ where experimental groups included only $5 \%$ of patients at risk of future hospital admission. In addition to the identification of frequent users based on data from hospital electronic medical records, opinion of healthcare providers is recommended to properly identify patients likely to be willing and able to participate in a CM intervention. ${ }^{38}$ Finally, many of the included studies had a small sample of frequent users ${ }^{10} 232829$ and could result in a lack of power where effects are harder to detect. The fact that frequent users are vulnerable populations who may be reluctant to participate ${ }^{39}$ and represent only a small proportion of patients ${ }^{1-3}$ could explain the low sample size of the included studies.

Our review has some limitations. Conducting a meta-analysis of the effectiveness of CM interventions for frequent users of healthcare services would have contributed to fill gaps in the possible lack of power of some included studies, but the heterogeneity across studies in terms of definition of frequent users, healthcare settings and CM interventions makes direct comparisons difficult. Another limitation of a scoping review is the potential omission of relevant articles, as well as any unpublished material. Our search strategy relied on key words assigned by authors and may have missed relevant studies on the effectiveness of CM. However, our search strategy was adapted for different databases, and enabled an exhaustive literature review. Moreover, we identified further articles through hand searching. Finally, it would be interesting to conduct an evaluation of the quality of the studies included. However, the scoping review method does not imply an evaluation of quality because it aims to provide a description of available research rather than determine robust or generalisable findings.

\section{CONCLUSION}

In conclusion, our review suggests that CM could reduce ED visits and hospitalisations as well as cost, but additional studies still need to clearly confirm its effectiveness. Pragmatic randomised controlled trials of adequate power and the recruitment of well-defined frequent users of healthcare services are needed. The effectiveness of CM to improve patient outcomes such as self-management and experience of care would also have to be evaluated.

\footnotetext{
Author affiliations

${ }^{1}$ Département de médecine de famille et de médecine d'urgence, Université de Sherbrooke, Sherbrooke, Québec, Canada

${ }^{2}$ Centre de recherche du Centre hospitalier universitaire de Sherbrooke, Sherbrooke, Quebec, Canada
}

${ }^{3}$ Département des sciences de la santé, Université du Québec à Chicoutimi, Saguenay, Québec, Canada

${ }^{4}$ Centre intégré universitaire de santé et de services sociaux du Saguenay-Lac-

Saint-Jean, Saguenay, Québec, Canada

${ }^{5}$ Département de pharmacologie-physiologie, Université de Sherbrooke, Sherbrooke, Québec, Canada

Acknowledgements The authors thank Ms Susie Bernier for her editorial assistance.

Contributors $\mathrm{CH}$ and $\mathrm{M}-\mathrm{CC}$ conceived the review and participated in its design and coordination. ML conducted the data collection and drafted the manuscript under the guidance of $\mathrm{CH}$ and $\mathrm{M}-\mathrm{CC}$. All authors were involved in drafting and editing the manuscript.

Funding This review was supported by the Canadian Institute of Health Research (ClHR).

Competing interests None declared.

Provenance and peer review Not commissioned; externally peer reviewed.

Data sharing statement No additional data are available.

Open Access This is an Open Access article distributed in accordance with the Creative Commons Attribution Non Commercial (CC BY-NC 4.0) license, which permits others to distribute, remix, adapt, build upon this work noncommercially, and license their derivative works on different terms, provided the original work is properly cited and the use is non-commercial. See: http:// creativecommons.org/licenses/by-nc/4.0/

\section{REFERENCES}

1. Bodenheimer T, Berry-Millett R. Follow the money-controlling expenditures by improving care for patients needing costly services. N Engl J Med 2009;361:1521-3.

2. Department of Health. Supporting people with long term conditions: an NHS and social care model to support local innovation and integration. UK: Department of Health, 2005.

3. Commission on the Reform of Ontario's Public Services. Public services for Ontarians: a path to sustainability and excellence. Ottawa: Queen's Printer for Ontario, 2012.

4. Althaus F, Paroz S, Hugli O, et al. Effectiveness of interventions targeting frequent users of emergency departments: a systematic review. Ann Emerg Med 2011;58:41-52.e42.

5. Kumar GS, Klein R. Effectiveness of case management strategies in reducing emergency department visits in frequent user patient populations: a systematic review. J Emerg Med 2013;44:717-29.

6. Hansagi $\mathrm{H}$, Olsson M, Sjöberg $\mathrm{S}$, et al. Frequent use of the hospital emergency department is indicative of high use of other health care services. Ann Emerg Med 2001;37:561-7.

7. Chan BT, Ovens HJ. Frequent users of emergency departments. Do they also use family physicians' services? Can Fam Physician 2002;48:1654-60

8. Byrne M, Murphy AW, Plunkett PK, et al. Frequent attenders to an emergency department: a study of primary health care use, medical profile, and psychosocial characteristics. Ann Emerg Med 2003;41:309-18.

9. Ruger JP, Richter CJ, Spitznagel EL, et al. Analysis of costs, length of stay, and utilization of emergency department services by frequent users: implications for health policy. Acad Emerg Med 2004;11:1311-7.

10. Lee KH, Davenport L. Can case management interventions reduce the number of emergency department visits by frequent users? Health Care Manag (Frederick) 2006;25:155-9.

11. Schoen C, Osborn R, Squires D, et al. New 2011 survey of patients with complex care needs in eleven countries finds that care is often poorly coordinated. Health Aff (Millwood) 2011;30:2437-48.

12. Brewster LR, Rudell LS, Lesser CS. Emergency room diversions: a symptom of hospitals under stress. Issue Brief Cent Stud Health Syst Change 2001:1-4.

13. Pillow MT, Doctor S, Brown S, et al. An Emergency Department-initiated, web-based, multidisciplinary approach to decreasing emergency department visits by the top frequent visitors using patient care plans. J Emerg Med 2013;44:853-60.

14. Shumway M, Boccellari A, O'Brien K, et al. Cost-effectiveness of clinical case management for ED frequent users: results of a randomized trial. Am J Emerg Med 2008;26:155-64. 
15. Soril LJ, Legget LE, Lorenzetti DL, et al. Reducing frequent visits to the emergency department: a systematic review of intervention. PLOS ONE 2015;10:e0123660.

16. National Case Management Network of Canada. Canadian standards of practice in case management. Ottawa: National Case Management Network of Canada, 2009.

17. Sutherland D, Hayter M. Structured review: evaluating the effectiveness of nurse case managers in improving health outcomes in three major chronic diseases. J Clin Nurs 2009;18:2978-92.

18. Grover CA, Close RJ, Villarreal K, et al. Emergency department frequent user: pilot study of intensive case management to reduce visits and computed tomography. West J Emerg Med 2010;11:336-43.

19. Singh D. Which staff improve care for people with long-term conditions: a rapid review of the literature. London: National Health Service Modernisation Agency, 2005.

20. Sweeney L, Halpert A, Waranoff J. Patient-centered management of complex patients can reduce costs without shortening life. Am J Manag Care 2007;13:84-92.

21. Rinke ML, Dietrich E, Kodeck T, et al. Operation care: a pilot case management intervention for frequent emergency medical system users. Am J Emerg Med 2012;30:352-7.

22. Segal L, Dunt D, Day SE, et al. Introducing co-ordinated care (1): a randomised trial assessing client and cost outcomes. Health Policy 2004;69:201-13.

23. Sledge $\mathrm{WH}$, Brown KE, Levine JM, et al. A randomized trial of primary intensive care to reduce hospital admissions in patients with high utilization of inpatient services. Dis Manag 2006;9:328-38.

24. Tadros AS, Castillo EM, Chan TC, et al. Effects of an emergency medical services-based resource access program on frequent users of health services. Prehosp Emerg Care 2012;16:541-7.

25. Arksey H, O'Malley L. Scoping studies: towards a methodological framework. Int J Soc Res Methodol 2005;8:19-32.

26. Armstrong R, Hall BJ, Doyle J, et al. Cochrane Update. 'Scoping the scope' of a cochrane review. J Public Health (Oxf) 2011;33:147-50.

27. Crane S, Collins L, Hall J, et al. Reducing utilization by uninsured frequent users of the emergency department: combining case management and drop-in group medical appointments. J Am Board Fam Med 2012;25:184-91.

28. Peddie S, Richardson S, Salt L, et al. Frequent attenders at emergency departments: research regarding the utility of management plans fails to take into account the natural attrition of attendance. N Z Med J 2011;124:61-6.

29. Phillips GA, Brophy DS, Weiland TJ, et al. The effect of multidisciplinary case management on selected outcomes for frequent attenders at an emergency department. Med J Aust 2006;184:602-6.

30. Shah R, Chen C, O'Rourke S, et al. Evaluation of care management for the uninsured. Med Care 2011;49:166-71.

31. Wetta-Hall R. Impact of a collaborative community case management program on a low-income uninsured population in Sedgwick County, KS. Appl Nurs Res 2007;20:188-94.

32. Craig P, Dieppe P, Macintyre S, et al. Developing and evaluating complex interventions: the new Medical Research Council guidance. Int J Nurs Stud 2013;50:587-92.

33. Petticrew M, Rehfuess E, Noyes J, et al. Synthesizing evidence on complex interventions: how meta-analytical, qualitative, and mixed-method approaches can contribute. J Clin Epidemiol 2013;66:1230-43.

34. Kne T, Young R, Spillane L. Frequent ED users: patterns of use over time. Am J Emerg Med 1998;16:648-52.

35. Locker TE, Baston S, Mason SM, et al. Defining frequent use of an urban emergency department. Emerg Med J 2007;24:398-401.

36. Barnett AG, van der Pols JC, Dobson AJ. Regression to the mean what it is and how to deal with it. Int J Epidemiol 2005;34:215-20.

37. Macpherson H. Pragmatic clinical trials. Complement Ther Med 2004;12:136-40.

38. Freund T, Gondan M, Rochon J, et al. Comparison of physician referral and insurance claims data-based risk prediction as approaches to identify patients for care management in primary care: an observational study. BMC Fam Pract 2013;14:157.

39. Gul RB, Ali PA. Clinical trials: the challenge of recruitment and retention of participants. J Clin Nurs 2010;19:227-33. 